\title{
FDG PET/CT in CIEDs infection: Don't wait any longer!
}

\author{
Eve Piekarski, MD, ${ }^{\mathrm{a}, \mathrm{b}, \mathrm{c}}$ Besma Mahida, MD, ${ }^{\mathrm{a}, \mathrm{b}, \mathrm{c}}$ François Rouzet, $M D, \operatorname{PhD},{ }^{\mathrm{a}, \mathrm{b}, \mathrm{c}}$ \\ and Dominique Le Guludec, MD, PhD ${ }^{a, b, c}$ \\ a Nuclear Medicine Department, Bichat Hospital, APHP, Paris, France \\ b Université de Paris, Paris, France \\ c INSERM, UMR 1148 (LVTS), Paris, France
}

Received Sep 4, 2020; accepted Sep 4, 2020

doi: 10.1007/s12350-020-02377-w

\section{See related article, pp. 594-608}

The rate of cardiac implantable electronic devices (CIEDs) infection is increasing despite preventive measures, and is associated with a poor prognosis with 30-day mortality of $5 \%$ to $8 \% .^{1}$ Optimal treatment which associates complete removal of all parts of the hardware and adequate antimicrobial therapy (according to bacteria identification whenever possible) enables to reduce the risk of events to a level close to that of patients with CIED and no infection. ${ }^{1,2}$ Infection of the generator pocket, which represents by far the most frequent type of CIED infection, ${ }^{3}$ is generally suspected on clinical examination based on signs ranging from mere local inflammation to purulent drainage or exposition of the hardware. Bloodstream infections such as vegetations attached to the leads and/or CIED-related infective endocarditis (CDRIE) are more challenging since systemic inflammation, bacteremia, metastatic septic foci (particularly in lungs) are non-specific. When transesophageal echocardiography is not conclusive, nuclear imaging approaches may be helpful in identifying abnormal signal (after a 2-month delay for FDG PET/ CT) at generator pocket site, along leads or valves site which are considered as major criteria, or distant septic emboli which are considered a minor criterion in the 2019 International CIED Infection Criteria. ${ }^{1}$

Reprint requests: Dominique Le Guludec, MD, PhD, Nuclear Medicine Department, Bichat Hospital, APHP, 46 rue Henri Huchard, 75018 Paris, France; dominique.leguludec@aphp.fr

J Nucl Cardiol 2022;29:609-11.

1071-3581/\$34.00

Copyright (C) 2020 American Society of Nuclear Cardiology.
This recent diagnostic flowchart ${ }^{1}$ is the transposition to CIEDs of the 2015 European Society of Cardiology recommendations for the diagnosis of prosthetic valves endocarditis. ${ }^{4}$ It should be emphasized that CIED pocket/generator infection is considered "definite", when relevant signs are present at clinical examination, obviating the need for further diagnostic procedures. ${ }^{1}$ In addition to the diagnosis of CIED infection, FDG PET/CT provides information on extracardiac findings ${ }^{5,6}$ such as metastatic septic foci, which may require dedicated treatment ${ }^{7}$ and/or infection entry site which treatment is mandatory to prevent relapse.

In a meta-analysis, Juneau et al reported an excellent diagnostic performance of FDG PET/CT in generator pocket site infections. ${ }^{8}$ In terms of the impact on clinical management, generator pocket infection is generally a clinical diagnosis and the British recommendations rightly point out that FDG PET/CT may be useful only when this diagnosis is uncertain. ${ }^{9}$ The diagnostic sensitivity of FDG PET/CT is lower in leads infection, ${ }^{8}$ in relation with limited spatial resolution of the technique and signal blurring on account of cardiac motion during acquisition. This limitation may be overcome by the detection of septic pulmonary emboli which are a frequent complication of CDRIE both at admission and during follow-up. ${ }^{10}$ When the diagnosis is not definite, the presence of septic pulmonary emboli is strongly suggestive of leads infection and/or CDRIE, ${ }^{5}$ hence both chest CT (showing peripheral lesions typically exhibiting wedge-shaped pattern with necrotic center) and PET (showing peripheral foci matching with nodules on CT) should be carefully analyzed.

In the present issue of Journal of Nuclear Cardiology, Jerónimo et al. prospectively evaluated the diagnostic performances of FDG PET/CT in 63 patients suspected of CIED infection, with a separate assessment 
of pocket and leads infections. ${ }^{11}$ The preparation and acquisition procedures complied with the recommendations for good practices, ${ }^{12}$ including a no carbohydrate diet. The final diagnosis was based on the endocarditis team decision, meaning that a subset of patients whom diagnosis would have been graded as "possible" infection according to the international guidelines ${ }^{1}$ have been finally graded as "rejected". As acknowledged by the authors, a CIED involvement cannot be completely excluded in patients who received full course antibiotics for definite left-sided infective endocarditis. Although the findings cannot be considered completely novel, they allow to highlight some important points.

First, the overall diagnostic performance of FDG PET/CT in this prospective study was in line with the results of the meta-analysis published in 2017, regarding both the high sensitivity in pocket infection and the good specificity in lead infection when considering FDG uptake only on the intracardiac portion of the leads. Noteworthy, in this study, the presence of extracardiac foci along the leads was non-specific in most cases since this pattern generally located at the most proximal part of the lead was related to an extension of the pocket infection. Also, ECG-gated acquisitions may possibly improve the detectability of abnormal uptake as recently shown in infective endocarditis. ${ }^{13}$

Secondly, the study corroborates that semi-quantitative analysis does not allow to discriminate between infected and non-infected devices. The authors performed the analysis based on attenuation-corrected data only (SUVmax or SUV ratio), entailing a risk of overcorrection artifacts. As suggested by some previous articles, there was no additional value compared with visual analysis, particularly in CDRIE. This points to the binary pattern of FDG uptake on CIEDs after 2 months post-implantation $^{6,14}$ : in the absence of infection there should be no FDG uptake along the generator or leads; otherwise the scan should be considered positive.

Third, the diagnostic impact of the time span between antibiotics initiation and PET/CT scan provided discrepant results according to studies. This one suggests the absence of relationship probably because the overall range was short (median 7 days) so that the difference between true positive and false negative cases was small (median 11 and 15 days respectively). As a comparison, the mean delay in false negative cases was 22 day in Diemberger et al. ${ }^{15}$ and 41 days in Calais et al. ${ }^{5}$ In any case, we must bear in mind that the scan must be programmed as soon as possible in the course of the disease to ensure optimal quality and maximal impact on the therapeutic management.

When considering the implementation of FDG PET/ $\mathrm{CT}$ in routine diagnostic work-up of CIED infections, its utilization is reported in only $26 \%$ of patients with suspected CDRIE in the EuroEndo survey. ${ }^{10}$ This is unsatisfactory given the wide availability of the technique. As a comparison, CT utilization is reported in a much greater proportion of patients, although mostly to search for extracardiac localizations. The survey also reported huge discrepancies between countries, western and northern Europe being the regions where FDG PET/ CT was the most widely used. ${ }^{10}$

Future developments may involve new specific tracers of infection, and potentially improvement in image analysis with artificial intelligence, but both are still at very preliminary stages.

In summary, FDG PET/CT performs very well in pocket infections but this diagnosis generally relies on clinical examination. On the other hand, the additional diagnostic value is major when bloodstream infection is suspected without definite evidence of hardware involvement. Now that the diagnostic performance of FDG PET/CT in CIED s infections is well established and the technique implemented in international flowcharts, ${ }^{1}$ a wider utilization should be fostered. Whenever possible, early imaging in the course of the disease is preferable to achieve maximal impact on patients' management.

\section{Disclosures}

Eve Piekarski, Besma Mahida, François Rouzet, and Dominique Le Guludec declare that they have no conflict of interest to disclose.

\section{References}

1. Blomström-Lundqvist C, Traykov V, Erba PA, Burri H, Nielsen JC, Bongiorni MG, Poole J, Boriani G, Costa R, Deharo J-C, Epstein LM, Sághy L, Snygg-Martin U, Starck C, Tascini C, Strathmore N. European Heart Rhythm Association (EHRA) international consensus document on how to prevent, diagnose, and treat cardiac implantable electronic device infections-endorsed by the Heart Rhythm Society (HRS), the Asia Pacific Heart Rhythm Society (APHRS), the Latin American Heart Rhythm Society (LAHRS), International Society for Cardiovascular Infectious Diseases (ISCVID), and the European Society of Clinical Microbiology and Infectious Diseases (ESCMID) in collaboration with the European Association for Cardio-Thoracic Surgery (EACTS). Eur Heart J. 2020;41:2012-32.

2. Rickard J, Tarakji K, Cheng A, Spragg D, Cantillon DJ, Martin DO, Baranowski B, Gordon SM, Tang WHW, Kanj M, Wazni O, Wilkoff BL. Survival of patients with biventricular devices after device infection, extraction, and reimplantation. JACC Heart Fail. 2013;1:508-13.

3. Krahn AD, Longtin Y, Philippon F, Birnie DH, Manlucu J, Angaran P, Rinne C, Coutu B, Low RA, Essebag V, Morillo C, Redfearn D, Toal S, Becker G, Degrâce M, Thibault B, Crystal E, Tung S, LeMaitre J, Sultan O, Bennett M, Bashir J, Ayala-Paredes F, Gervais P, Rioux L, Hemels MEW, Bouwels LHR, van Vlies B, 
Wang J, Exner DV, Dorian P, Parkash R, Alings M, Connolly SJ. Prevention of arrhythmia device infection trial: The PADIT trial. J Am Coll Cardiol. 2018;72:3098-109.

4. Habib G, Lancellotti P, Antunes MJ, Bongiorni MG, Casalta J-P, Del Zotti F, Dulgheru R, El Khoury G, Erba PA, Iung B, Miro JM, Mulder BJ, Plonska-Gosciniak E, Price S, Roos-Hesselink J, Snygg-Martin U, Thuny F, Tornos Mas P, Vilacosta I, Zamorano JL, Document Reviewers, Erol Ç, Nihoyannopoulos P, Aboyans V, Agewall S, Athanassopoulos G, Aytekin S, Benzer W, Bueno H, Broekhuizen L, Carerj S, Cosyns B, De Backer J, De Bonis M, Dimopoulos K, Donal E, Drexel H, Flachskampf FA, Hall R, Halvorsen S, Hoen B, Kirchhof P, Lainscak M, Leite-Moreira AF, Lip GYH, Mestres CA, Piepoli MF, Punjabi PP, Rapezzi C, Rosenhek R, Siebens K, Tamargo J, Walker DM. ESC Guidelines for the management of infective endocarditis: The Task Force for the Management of Infective Endocarditis of the European Society of Cardiology (ESC). Endorsed by: European Association for Cardio-Thoracic Surgery (EACTS), the European Association of Nuclear Medicine (EANM). Eur Heart J. 2015;2015(36):3075128.

5. Calais J, Touati A, Grall N, Laouénan C, Benali K, Mahida B, Vigne J, Hyafil F, Iung B, Duval X, Lepage L, Le Guludec D, Rouzet F. Diagnostic impact of 18F-fluorodeoxyglucose positron emission tomography/computed tomography and white blood cell SPECT/computed tomography in patients with suspected cardiac implantable electronic device chronic infection. Circ Cardiovasc Imaging. 2019;12:e007188.

6. Salomäki SP, Saraste A, Kemppainen J, Hurme S, Knuuti J, Nuutila P, Seppänen M, Roivainen A, Airaksinen J, Salo T, Oksi J, Pirilä L, Hohenthal U. 18F-FDG positron emission tomography/computed tomography of cardiac implantable electronic device infections. J Nucl Cardiol. 2020. https://doi.org/10.1007/ s12350-015-0325-y.

7. Calais J, Pasi N, Nguyen V, Hyafil F. Mycotic aneurysm in a pulmonary artery detected with $18 \mathrm{~F}$-fluorodeoxyglucose positron emission tomography/computed tomography imaging. Eur Heart $J$ [Internet] 2017. Available from: http://www.ncbi.nlm.nih.gov/pub $\operatorname{med} / 28057774$.

8. Juneau D, Golfam M, Hazra S, Zuckier LS, Garas S, Redpath C, Bernick J, Leung E, Chih S, Wells G, Beanlands RSB, Chow BJW. Positron emission tomography and single-photon emission computed tomography imaging in the diagnosis of cardiac implantable electronic device infection: A systematic review and meta-analysis. Circ Cardiovasc Imaging. 2017. https://doi.org/10. 1161/CIRCIMAGING.116.005772.

9. Sandoe JAT, Barlow G, Chambers JB, Gammage M, Guleri A, Howard P, Olson E, Perry JD, Prendergast BD, Spry MJ, Steeds RP, Tayebjee MH, Watkin R, British Society for Antimicrobial Chemotherapy, British Heart Rhythm Society, British
Cardiovascular Society, British Heart Valve Society, British Society for Echocardiography. Guidelines for the diagnosis, prevention and management of implantable cardiac electronic device infection. Report of a joint Working Party project on behalf of the British Society for Antimicrobial Chemotherapy (BSAC, host organization), British Heart Rhythm Society (BHRS), British Cardiovascular Society (BCS), British Heart Valve Society (BHVS) and British Society for Echocardiography (BSE). J Antimicrob Chemother. 2015;70:325-59.

10. Habib G, Erba PA, Iung B, Donal E, Cosyns B, Laroche C, Popescu BA, Prendergast B, Tornos P, Sadeghpour A, Oliver L, Vaskelyte J-J, Sow R, Axler O, Maggioni AP, Lancellotti P, EURO-ENDO Investigators. Clinical presentation, aetiology and outcome of infective endocarditis. Results of the ESC-EORP EURO-ENDO (European infective endocarditis) registry: a prospective cohort study. Eur Heart J. 2019;40:3222-32.

11. Jerónimo A, Olmos C, Vilacosta I, Ortega-Candil A, RodríguezRey C, Pérez-Castejón MJ, Fernández-Pérez C, Pérez-García CN, García-Arribas D, Ferrera C, Carreras JL. Accuracy of 18F-FDG $\mathrm{PET} / \mathrm{CT}$ in patients with the suspicion of cardiac implantable electronic device infections. J Nucl Cardiol. 2020. h ttps://doi.org/10.1007/s12350-020-02285-z.

12. Erba PA, Lancellotti P, Vilacosta I, Gaemperli O, Rouzet F, Hacker M, Signore A, Slart RHJA, Habib G. Recommendations on nuclear and multimodality imaging in IE and CIED infections. Eur J Nucl Med Mol Imaging. 2018;45:1795-815.

13. Boursier C, Duval X, Bourdon A, Imbert L, Mahida B, Chevalier E, Claudin M, Hoen B, Goehringer F, Selton-Suty C, Roch V, Lamiral Z, Humbert O, Rouzet F, Marie P-Y, AEPEI-TEPvENDO study group. ECG-gated cardiac FDG PET acquisitions significantly improve detectability of infective endocarditis. JACC Cardiovasc Imaging. 2020. https://doi.org/10.1016/j.jcmg.2020.06. 036.

14. Sarrazin J-F, Philippon F, Tessier M, Guimond J, Molin F, Champagne J, Nault I, Blier L, Nadeau M, Charbonneau L, Trottier M, O'Hara G. Usefulness of fluorine-18 positron emission tomography/computed tomography for identification of cardiovascular implantable electronic device infections. J Am Coll Cardiol. 2012;59:1616-25.

15. Diemberger I, Bonfiglioli R, Martignani C, Graziosi M, Biffi M, Lorenzetti S, Ziacchi M, Nanni C, Fanti S, Boriani G. Contribution of PET imaging to mortality risk stratification in candidates to lead extraction for pacemaker or defibrillator infection: A prospective single center study. Eur J Nucl Med Mol Imaging. 2019;46:194205 .

Publisher's Note Springer Nature remains neutral with regard to jurisdictional claims in published maps and institutional affiliations. 